Sukamta, Sudarja, Budi Nurrahman, Berli Paripurna Kamiel, Sudarisman Program Studi Teknik M esin, Fakultas Teknik U niversitas M uhammadiyah Yogyakarta

Jalan Brawijaya Tamantirto, Kasihan, Bantul, Daerah Istimewa Yogyakarta 55183 Email: sukamta@umy.ac.id

\section{Peningkatan Kemandirian Desa Melalui Pembangunan Instalasi Perpipaan Air Bersih dari Sumber Mata Air ke Rumah Penduduk}

The Improvement of Village Independence through the $\mathrm{C}$ onstruction of C lean Water Piping Installation from the Springs to the V illagers' H ouses

https:/ / doi.org/ 10.18196/ bdr.7152

\begin{abstract}
Community empowerment program to make a village independent is very important. Village independence could be seen from various aspects, and one of which is the aspect of independence in the provision of clean water. Clean water supply activities in Balong Hamlet, Donoharjo Village, Ngaglik Sub- District, Sleman Regency are community empowerment activities in order to make Balong Hamlet independent on the aspect of the ability to provide clean water. This activity began with a survey and data collection of local residents' water needs, followed by calculation of clean water requirements, design of clean water supply and distribution systems, implementation of piping installation, commissioning tests, economic analysis, and its contribution in making the village independent of clean water. This activity produces a piping system for clean water from the spring to the houses of Balong hamlets with a population of approximately 203 households. On average, each household needs 600 liters/day so it requires $121.8 \mathrm{~m}^{3} /$ day or $3654 \mathrm{~m}^{3} /$ month. The price of standard clean water for the Drinking Water Company (PAM) is Rp1,960.00/ $\mathrm{m}^{3}$, so the hamlet has saved Rp7,161,840.00/month or Rp85,942,080.00/year. Thus, this activity has made Balong Hamlet contribute significantly to the independence of Donoharjo Village: Keywords: clean water, piping installation, Balong, independent village.
\end{abstract}

\title{
PENDAHULUAN
}

Air merupakan sumber penghidupan bagi manusia, baik digunakan untuk memenuhi kebutuhan dasar sebagai air minum dan kebutuhan pokok lain maupun untuk menjaga keberlangsungan sumber mata pencahariannya untuk pengai ran (irigasi) pertanian. O leh karenanya, air tidak boleh hanya dipandang sebagai entitas sumber daya alam semata, namun iajuga memiliki fungsi dan manfaat yangsignifikan bagi kehidupan umat manusia. Dengan demikian, pengelolaan sumber daya air yang tepat dan serius serta mampu memenuhi kebutuhan masyarakat mutlak diperlukan (Fakhrina, 2013). Telah dilakukan observasi lapangan dan diketahui bahwa bahwa tata kelola sumber air bersih di suatu desa sangat diperlukan guna menjadikan suatu desa menjadi mandiri (Marfai dan $C$ ahyadi, 2017). Sistem penyediaan air bersih merupakan salah satu komponen prasarana 
kota dan sekarang telah berkembang ke desa yang terdekat dengan kota. Prasarana kota memegang peranan yang sangat penting bagi pertumbuhan dan perkembangan suatu kota. Prasarana dapat memberi dampak terhadap peningkatan taraf dan mutu kehidupan masyarakat, pola pertumbuhan, dan prospek perkembangan ekonominya. Air bersih merupakan salah satu hal yang penting dan mendapat prioritas dalam perencanaan kota (C atanese dan Snyder, 1994). Tanggungjawab penyediaan prasarana dan pelayanan perkotaan ditanggung bersama oleh pemerintah pusat dan daerah berdasarkan prinsip dekonsentrasi, desentralisasi, dan pembantuan (Rukmana et.al., 1993). Penyediaan air bersih pada prinsipnya diutamakan bagi masyarakat yang belum memiliki aksesterhadap air bersih. (Kodoatie, 2003). M elalui Peraturan Pemerintah Nomor 20 Tahun 1994 telah diatur kesempatan peran serta masyarakat dan dunia usaha termasuk untuk kegiatan yang penting bagi negara dan menguasai hajat hidup orang banyak, diantaranya dalam penyediaan air bersih (Kodoatie et.al., 2002). Tidak terkecuali untuk Padukuhan Balong, air bersih merupakan kebutuhan primer yang sangat diperlukan untuk keperluan mandi, cuci, dan minum masyarakat. Padukuhan Balong berada di desa Donoharjo yang merupakan bagian dari wilayah Kecamatan Ngaglik, Kabupaten Sleman, Daerah Istimewa Yogyakarta, Indonesia. D esa D on oharjo terletak di Jalan Palagan Tentara Pelajar Km. 13 dan berpenduduk 15.817 jiwa. Padukuhan Balong berpenduduk 203 kepala keluarga (KK) atau 618 warga. Secara umum masyarakat Padukuhan Balong mengonsumsi air bersih dari sumur dangkal, namun karena kondisi tanah yang men gandung pasir besi maka kualitas air bersihnya kurang baik sehingga kurang layak dikonsumsi karena berwarna jernih kekuningkuningan dan berbau besi. Jika harus menggunakan air dari PAM maka menjadi mahal, yaitu Rp1.960,00/ $\mathrm{m}^{3}$. Perlu diketahui bahwa berdasarkan data survei, jumlah kebutuhan ratarata untuk setiap KK adalah 500 liter/ hari atau 15 $\mathrm{m}^{3}$ / bulan. Sehinggajika harus menggunakan air dari PAM setiap KK harus mengeluarkan biaya Rp29.400,00/ bulan. Jika dihitung untuk semua warga masyarakat Balong yang berjumlah 203 KK maka diperlukan biaya Rp5.968.200,00/ bulan. Oleh karena itu, kegiatan pemberdayaan masyarakat melalui pembangunan sistem instalasi air bersih dari sumber mata air ke rumah penduduk di Padukuhan Balong ini memberikan dampak yang sangat signifikan, dan dapat meringankan beban masyarakat khususnya dalam kemandirian penyediaan air bersih.

\section{METODE PELAKSANAAN}

Program kegiatan ini dilaksanakan beberapa metode antara lain : 
a. Observasi dan Pemetaan Kebutuhan Air Bersih

O bservasi dilakukan untuk meninjau wilayah Pedukuhan Balong secara keseluruhan. Pelaksanaan dilakukan dengan cara melakukan wawancara dengan segenap komponen masyarakat, seperti perangkat desa dan warga masyarakat serta melihat kondisi lapangan secara langsung. Pemetaan ini untuk memperjelas keadaan dan karakteristik padukuhan ini terkait kebutuhan air bersih. Pemetaan ini dapat dijadikan sebagai acuan untuk menentukan langkah selanjutnya.

\section{b. Sosialisasi}

Sebelum pelaksanaan seluruh rangkaian kegiatan pengabdian masyarakat ini dimulai, perlu diadakan sosialisasi mengenai program ini pada Ketua RT, Ketua RW, dan Kepala D esa setempat serta masyarakat. Tujuan kegiatan ini adalah agar masyarakat memahami program tersebut dan tidak terjadi kesalahpahaman dalam pelaksanaan program. Selain itu, sosialisasi juga berfungsi untuk menggali lebih dalam mengenai permasalahan yang dialami masyarakat dan solusi yang dibutuhkan. Dengan begitu, diharapkan program pengabdian masyarakat ini dapat menghasilkan luaran yang sesuai dengan keinginan dan kebutuhan masyarakat.

\section{c. Lokasi Pelaksanaan}

Lokasi pelaksanan program ini yaitu di Padukuhan Balong, Desa Donoharjo, Kecamatan N gaglik, Kabupaten Sleman, D aerah Istimewa Yogyakarta.

\section{d. Pelaksanaan Program}

Rangkaian kegiatan program pengabdian masyarakat yang akan dilakukan meliputi beberapa tahap:

1) Perhitungan Kebutuhan Air Bersih

Pada kegiatan ini dilakukan perhitungan kebutuhan air bersih masyarakat berdasarkan jumlah anggota setiap kepala keluarga (KK). Berdasarkan pada hasil observasi sebelumnya, diperoleh data bahwa Padukuhan Balong berjumlah 203 KK atau 618 orang anggota keluarga. M enurut standar perhitungan kebutuhan air bersih per orang memerlukan 160-250 liter/ hari (N oerbambang M ,Soufyan et.al., 2005). Sehingga untuk 618 orang diperlukan minimal $98,8 \mathrm{~m}^{3}$ / hari. Jika dihitung berdasarkan jumlah KK maka diperoleh kebutuhan air bersih 14,6 m3/ bulan/ KK atau 487 liter/hari/ KK. Sesuai hasil survei lapangan diperoleh data bahwa kebutuhan air bersih penduduk 
ratarata adalah 500 liter/ hari/ KK atau 101,5 m³/ hari untuk $203 \mathrm{KK}$ di padukuhan Balong. Jadi kedua hasil perhitungan dan survei tersebut bersesuaian.

2) Perancangan Sistem Suplai dan Distribusi Air Bersih

Perancangan sistem suplai air bersih dan pemanfaatan sumber mata air dilakukan dengan menghitung kebutuhan volume bak penampungan sumber air. Selanjutnya, dirancang kebutuhan pipa dan sistem instalasi dari hulu ke hilir lengkap dengan sistem kontrol. Perancangan sistem distribusi harus mempertimbangkan kebutuhan debit aliran dan material pipa serta konstruksi sistem perpipaan berdasarkan standar Pengembangan Sistem Penyediaan Air M inum (Indonesia, 2005).

3) Pelaksanaan Pemasangan Instalasi Perpipaan

Pada tahap ini warga masyarakat bekerjasama dengan tim pengabdian masyarakat melakukan pemasangan instalasi perpipaan air bersih dari sumber mata air sampai ke rumah penduduk di Padukuhan Balong.

4) Commisioning Test

Pada tahap ini dilakukan tes ujicoba (commisioning test) untuk menguji apakah sistem instalasi berfungsi dengan baik atau tidak. H asil dari tes ini ternyata menghasilkan bahwa sistem berfungsi dengan baik, terbukti air mengalir sampai kerumah penduduk dengan lancar.

5) Analisis Ekonomi

Pada tahap ini dilakukan analisis ekonomi, yaitu dengan menghitung seberapa besar manfaat yang diterima oleh masyarakat ditinjau dari sudut pandang ekonomi. O leh karena itu dapat diketahui apakah program ini memberi dampak signifikan terhadap kemandirian desa terhadap air bersih atau tidak.

6) Evaluasi dan Tindak lanjut

Evaluasi dilakukan untuk mengetahui seberapa efektif program ini dan seberapa besar manfaat atau kontribusinya kepada masyarakat. Tindaklanjut program ini sangat diperlukan untuk menjamin keberlangsungan pembanguan kemandirian desaterhadap kebutuhan air bersih.

\section{HASIL DAN PEMBAHASAN}

a. Hasil Pengabdian Kepada Masyarakat

Kegiatan pengabdian masyarakat ini dilaksanakan di Padukuhan Balong, Kecamatan N galik, Kecamatan Sleman, Yogyakarta, seperti ditunjukkan pada gambar 1. Kegiatan diawali dengan observasi dan pemetaan kebutuhan air bersih Padukuhan Balong. 
Berdasarkan survei lapangan diperoleh data kebutuhan masyarakat adalah 98,88 $\mathrm{m}^{3} /$ hari, sementara sumber mata air yang berjarak lebih kurang 2 km dari Padukuhan Balong dengan beda elevasi $10 \mathrm{~m}$ memiliki debit 3 liter/ detik atau 129,6 m³/ hari. Sehingga debit air yang tersedia mencukupi kebutuhan masyarakat. O leh karena itu kemudian dibuat penampungan air di bagian hulu dengan ukuran $150 \mathrm{~m}^{3}$ seperti ditunjukkan pada gambar 2 dan 3. Selanjutnya, air disalurkan melalui pipa G alvanized I ron Pipe (GIP) dan flexible pipeyang berdiamter 2 in, 1,5 in, dan 1 in sampai ke bak penampungan air di hilir seperti dapat dilihat pada gambar 4 sampai dengan 6 .

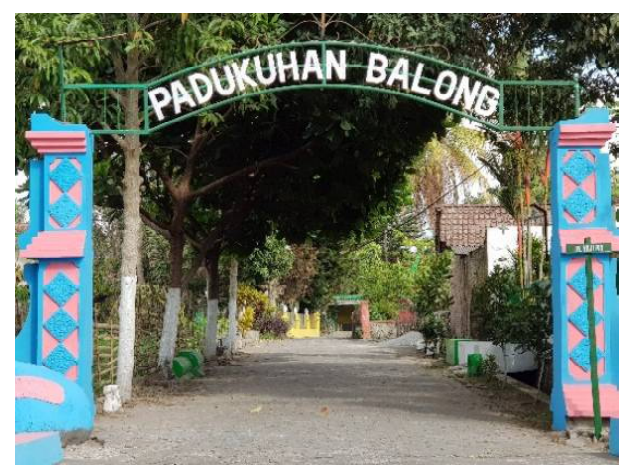

Gambar 1. Lokasi pengabdian masyarakat

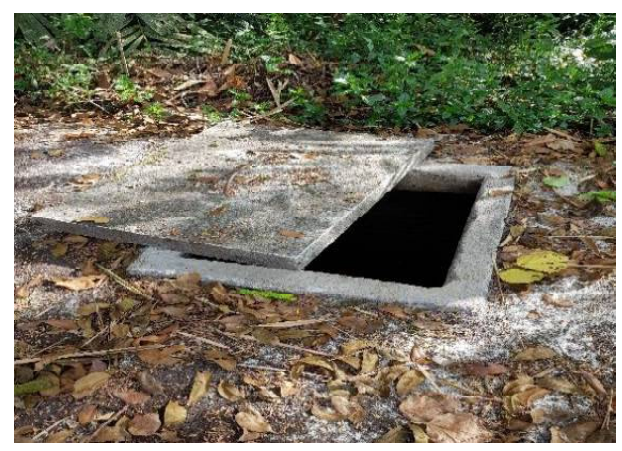

Gambar 3. Sisi atas bak penampungan air hulu Gambar

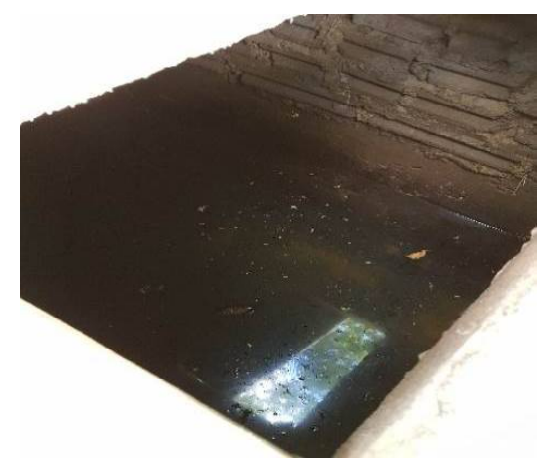

Gambar 2. Sisi dalam bak penampungan air hulu

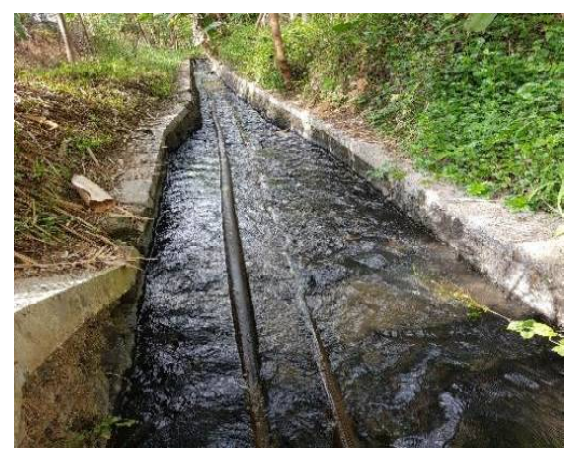

4. J aringan pipa hulu

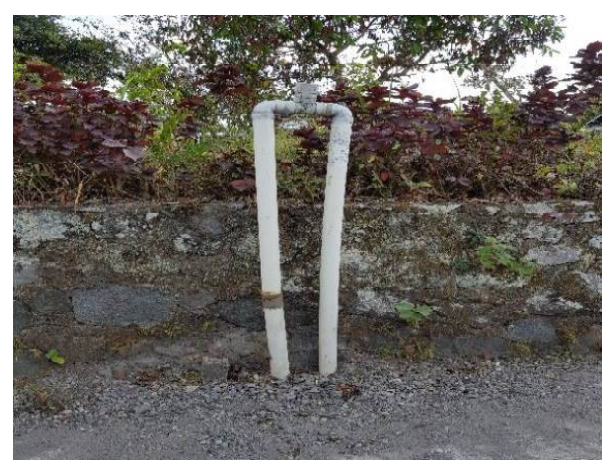

Gambar 5. Sistem kontrol aliran air

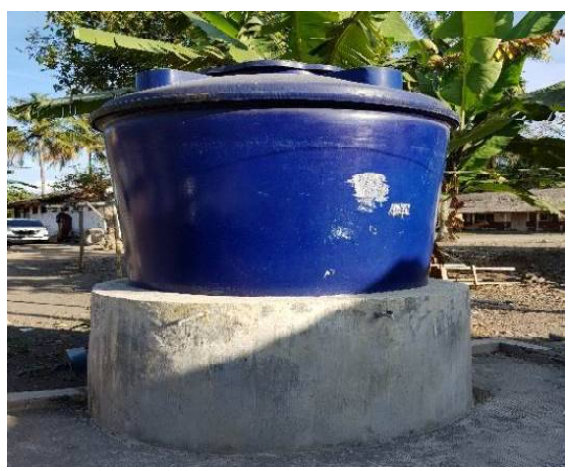

Gambar 6. Penampungan air di hilir 


\section{9}

Untuk mencegah terjadinya penurunan tekanan berlebihan di jaringan pipa yang dapat mengakibatkan aliran air tidak lancar, maka dipasang katup kontrol seperti dilihat pada gambar 5. Selanjutnya, dialirkan ke bak penampungan air di hilir yang sebenarnya langsung dapat dimanfaatkan secara langsung melalui kran yang dipasang pada bagian bawah seperti ditunjukkan pada gambar 6 . Selain itu, air juga dialirkan langsung ke masing-masing rumah penduduk untuk kebutuhan mandi, cuci , m dan minum seperti ditunjukkan pada gambar 7 sampai dengan 10 .

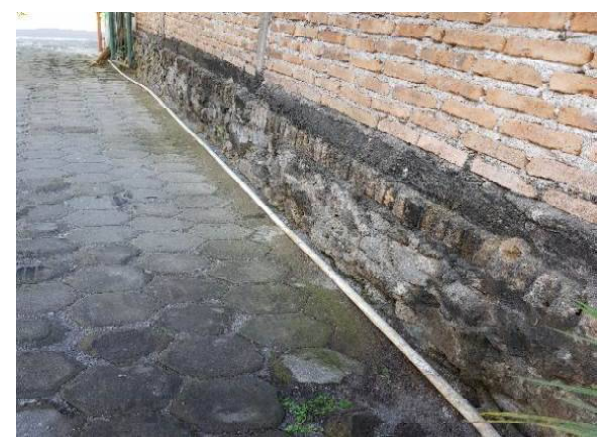

Gambar 7. J aringan Pipa hulu

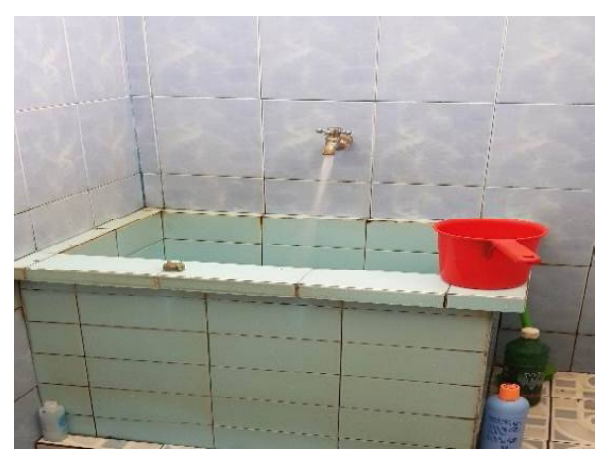

Gambar 9. J aringan Pipa hulu

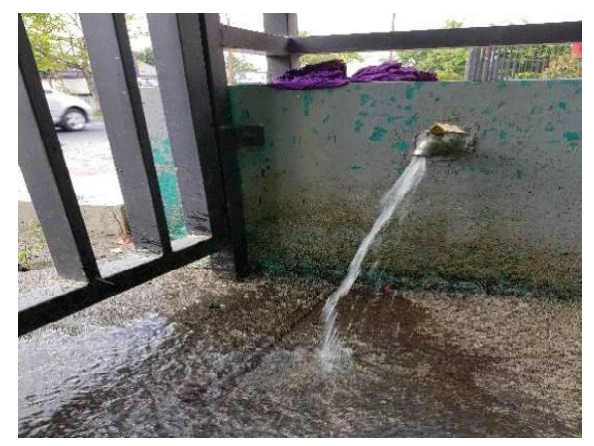

Gambar 8. Sistem kontrol aliran air

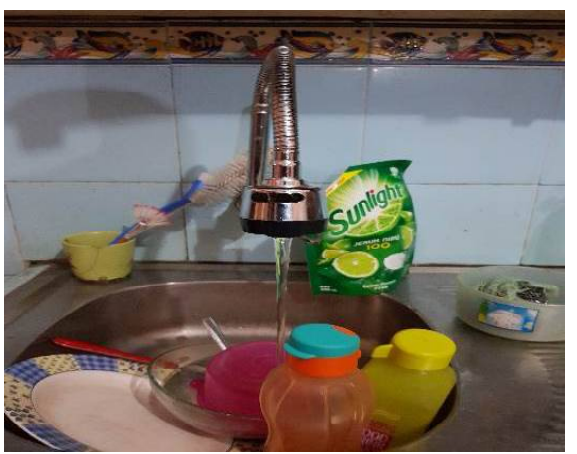

Gambar10. Sistem kontrol aliran air

\section{b. Pembahasan}

Sesuai hasil survei lapangan diperoleh data bahwa kebutuhan air bersih penduduk ratarata adalah 500 liter/ hari/ KK atau 101,5 m³/hari untuk $203 \mathrm{KK}$ di padukuhan Balong $\mathrm{H}$ arga air bersih standar Perusahaan Air M inum (PA M) adalah Rp1.960,00/ m³, maka padukuhan tersebut telah menghemat R p198,940,00/ hari atau Rp5.968.200,00/ bulan atau $71.618 .400,00 /$ tahun. Pada kegiatan ini juga dilakukan perhitungan dan analisis ekonomi meliputi biaya investasi, pendapatan ekivalen, Benefit C ost Ratio (B/C), Payback Period (PP).

Biaya investasi keseluruhan yang digunakan untuk penyediaan air bersih ini sebesar Rp 52 juta. Biaya yang diperlukan untuk operasional dan perawatan sebesar 6 juta/ 
tahun. Sehingga keuntungan ekivalensi bersih setiap tahun adalah Rp 66,6 juta. D engan demikian, Perhitungan Benefit $C$ ost Ratio $(B / C)$ untuk mengetahui perbandingan antara keuntungan dan biaya yang telah dikeluarkan untuk waktu 1 tahun diperoleh $\mathrm{Rp}$ 66,6 Juta dibagi Rp58 juta dan menghasilkan 1,14. Dari perhitungan di atas didapatkan nilai B/C >1 yang berarti kegiatan ini layak untuk dijalankan. Sedangkan Payback Period (PP) digunakan untuk untuk melihat jangka waktu yang dibutuhkan terhadap pengembalian modal yang dikeluarkan. Untuk mengetahui lamanya modal kembali, dapat dengan menggunakan rumus payback period yaitu Total modal kerja dibagi keuntungan yaitu $\mathrm{Rp}$ 58 juta dibagi 60,6 juta yang menghasilkan 0,96 tahun atau setara dengan 11 bulan. Kegiatan ini bersesuaian dengan yang dilakukan oleh pengabdi sebelumnya di daerah lain yaitu program yang membentuk masyarakat mandiri dan sadar lingkungan dalam men gelola sumber daya air, meningkatkan kesejahteran masyarakat dalam pembangunan desa, menciptakan teknologi sistem pengolahan air pipanisasi, meningkatkan pengetahuan dan kemampuan kelompok mitra dalam men gelolah penerapan man ajemen pengolahan air, meningkatkan kepedulian kelompok tani dan masyarakat dalam berkehidupan yang sehat, bersih, dan aman (Mas'ud, Patriya, dan Sasongko, 2017). Kegiatan pemberdayaan masyarakat untuk bidangyang sedikit berbedatetapi masi $\mathrm{h}$ dalam rangka menjadikan masyarakat mandiri juga pernah dilakukan (Sukamta et.al., 2017). Demikian pula terkait dengan pengalaman melakukan pemberdayaan masyarakat khususnya terkait dengan upaya meningkatkan partisipasi masyarakat dalam pembangunan dan pengelolaan prasarana penyediaan air bersih di suatu desa pernah dilaksanakan pada waktu sebelumnya (Sumiyarsono, 2010).

\section{SIMPULAN}

Dari uraian dan analisis pada pembahasan dapat disimpulkan bahwa kegiatan Pembangunan Instalasi Perpipaan Air Bersih dari Sumber M ataAir keRumah Penduduk di Padukuhan Balong D onoharjo N gaglik Sleman Yogyakarta ini telah mampu mendorong padukuhan ini menjadi padukuhan yang mandiri dalam hal penyediaan air bersih. $\mathrm{Hal}$ ini ditunjukkan dengan perhitungan Perhitungan Benefit C ost Ratio (B/C) sebesar 1,14 yang berarti kegiatan ini layak untuk dijalankan dan Payback Period sebesar 0,96 tahun atau setara dengan 11 bulan.

\section{UCAPAN TERIMA KASIH}

Penghargaan dan ucapan terima kasih diberikan kepada Teddy Nurcahyadi, Wahyudi, 
M uhammad Nadjib, Tito Hadji A gung Santosa, Novi Caroko, Aris W idyo Nugroho, Sunardi, Totok Suwanda, Bambang Riyanta dan segenap masyarakat padukuhan Balong yang telah terlibat di dalam kegiatan pen gabdian kepada masyarakat ini. D emikian aprisiasi disampaikan kepada U niversitas M uhammadiyah Yogyakarta atas dukungan pendanaannya.

\section{DAFTAR PUSTAKA}

Catanese, J. Anthony and Snyder, C. James.1994. Perencanaan Kota.Terjemahan. Jakarta.Penerbit Erlangga.

Fakhrina, A. (2013). Pengelolaan Sumber Daya Air Di Dukuh Kaliurang: Perspektif Ekonomi Islam. JURNAL PENELITIAN, 9(1).

Kodoatie, Robert J., Basoeki. 2005. Kajian UndangUndang Sumber Daya Air. Yogyakarta.Penerbit Andi. INDONESIA, P. R. (2005). Peraturan Pemerintah Republik Indonesia Nomor 16 Tahun 2005 Tentang Pengembangan Sistem Penyediaan Air Minum. Republik Indonesia.

Marfai, M. A., \& Cahyadi, A. (2017). Analisis Pola Adaptasi Masyarakat Terhadap Keterbatasan Sumberdaya Air Di Pesisir Kabupaten Demak. Mas'ud, M., Patriya, R. N., \& Sasongko, J. (2017). Pengolahan Sumber Daya Air Untuk Meningkatkan Kesejahteraan Masyarakat Di Desa Karangrejo Dusun Gutean Kecamatan Purwosari Kabupaten Pasuruan. ENGAGEMENT, 1(1), 1-13.

Noerbambang, S., M orimura T. 1993. Perancangan dan Pemeliharaan Sistem Plumbing.J akarta. Penerbit Pradnya Paramita.

Rukmana, Nana et.al.1993. Manajemen Pembangunan Prasarana Perkotaan. Penerbit LP3ES.J akarta.

Sukamta, MA Shomad, A Wisnujati.2017.Pengelolaan Limbah Ternak Sapi Menjadi Pupuk Organik Komersial di Dusun Kalipucang, Bangunjiwo, Bantul, Yogyakarta. BERDIKARI: Jurnal Inovasi dan Penerapan Ipteks, Penerbit Lp3M UMY. Yogyakarta Sumiyarsono, E. (2010). Partisipasi Masyarakat Dalam Pembangunan Dan Pengelolaan Prasarana Penyediaan Air Bersih Di Desa Wawoosu Dan Desa Mataiwoi Kecamatan Kolono Kabupaten Konawe Selatan Provinsi Sulawesi Tenggara (PhD Thesis). Universitas Diponegoro. 